\title{
Effects of Irrigation Solutions on Root Canal Dentin
}

\author{
Paulina Grinkevičiūtė, DDS \\ Gintarè Leknickè, DDS \\ Greta Lodienė, DDS, PhD \\ Lithuanian University of Health Sciences \\ Odontology Faculty, \\ Department of Dental and Oral Pathology \\ Eivenių str. 2, LT-50161 Kaunas \\ Lithuania \\ Rita Kriūkienė, PhD \\ Research Associate \\ Lithuanian Energy Institute \\ Laboratory of materials research and testing \\ Breslaujos str. 3, LT-44403 Kaunas \\ Lithuania
}

\begin{abstract}
The aim of the study was to determine the irrigation solutions impaction on the root canal dentin micro-hardness and surface erosion. All irrigation solutions significantly decreased root canal dentin microhardness $(P<0.05)$. The greatest reduction was induced by Dual Rinse HEDP $(P<0.05)$, while 17\% EDTA and 17\% EDTA + 2.5\% NaOCl showed a similar reduction with no significant difference $(P>0.05)$. SEM analysis did not show any erosion of the dentin surface in the randomly selected specimens. In this study, irrigation solutions have not induced root canal dentin erosion, but significantly reduced the dentin micro-hardness. The greatest reduction was induced by Dual Rinse HEDP.
\end{abstract}

Keywords: Vickers hardness test, dentin micro-hardness, sodium hypochlorite, EDTA, SEM.

\section{Introduction}

One of the purposes of endodontic treatment is to disinfect the root canal system, eliminate the microorganisms, their products and protect against the reinfection. The complexity of root canal system complicates the mechanical cleaning of the canal and the removal of the biofilm as well (Plotino et al. 2016). Irrigation solutions affect the chemical composition of dentin, which may have an impact on its physical properties (Pashley et al. 1985). Erosion around dentin tubules results from the effects of the irrigation solution on collagen (Wagner et al. 2017). When sodium hypochlorite $(\mathrm{NaOCl})$ is used alone, and the collagen fiber is covered with hydroxyapatite, then the solution is limited to dentin. However, if a decalcification solution is used, hydroxyapatites are removed and thus collagen fibers are uncovered. The sodium hypochlorite solution then has a direct effect on the protein (collagen) and over a fairly short time causes significant collagen destruction, which could change the bending elasticity of the dentin (Grigoratos et al. 2001, Tartari et al. 2018). It was shown that $17 \%$ ethylenediaminetetraacetic acid (EDTA) and $2.5 \% \mathrm{NaOCl}$ irrigation for $1 \mathrm{~min}$. removes more $\mathrm{Ca}^{2+}$ ions from the root canal dentin than using 17\% EDTA alone (Sayin et al. 2007). Due to the changes in organic and inorganic materials, micro-fluidity in the dentine may occur which could reduce the fracture resistance to fracture (Uzunoglu et al. 2012). Recently, etidronate (HEBP), a substance that prevents bone resorption has been used in medicine for patients suffering from osteoporosis or Paget's disease and was suggested as substitute for traditional chelators due to fewer effects observed on dentin structure (Tartari et al. 2013). According to literature, etidronic acid has a less impact on dentin structure than EDTA (Ulosoy et al. 2017). EDTA was found to inhibit the ability of $\mathrm{NaOCl}$ to dissolve organic tissues, while 1-hydroxyethane 1,1-diphosphonic acid (HEDP) had a slight effect on this sodium hypochlorite property (Tartari et al. 2015). Using $2.5 \% \mathrm{NaOCl}$ in combination with $9 \%$ etidronic acid, the smear layer is removed in a similar way to EDTA or citric acid (Gautschi et al. 2009). Thus, while treating dentin with $\mathrm{HEBP}$ and $\mathrm{NaOCl}$, the latter's antibacterial properties are not lost and one universal irrigation solution is obtained (De-Deus et al. 2008). Solutions for the last canal irrigation prior to obturation are important for the root canal filling quality and the long-term tooth prognosis. 
The use of EDTA before root canal filling has been shown to improve the antibacterial properties of root canal sealers (Ulosoy et al. 2017). If sodium hypochlorite is used during the last irrigation, resistance to vertical root fracture is reduced (Uzunoglu et al. 2012). It is important to evaluate the duration of irrigation and concentration of solutions in order to minimize dentin erosion (Uzunoglu et al. 2012). Recently, Dual Rinse HEDP (Medcem GmbH, Switzerland) was introduced. According to the manufacturers, this single product is efficient for root canals irrigation due to physicochemical properties and reduces the probability of the occurrence of undesirable chemical reactions by mixing of irrigation solutions. Recently was found that irrigation with Dual Rinse HEDP significantly improved the push out bond strength of Biodentine to the root canal dentin (Paulson et al. 2018).

The aim of the study was to determine irrigation solutions impaction on the root canal dentin micro-hardness and surface erosion. The null hypothesis was that solutions used for the last root canal irrigation prior to obturation: $17 \%$ EDTA, EDTA in combination with $2.5 \% \mathrm{NaOCl}$ and Dual Rinse HEDP reduce dentin microhardness and cause changes in the dentin surface structure.

\section{Materials and methods}

Lithuanian University of Health Sciences Bioethical Center has approved the research (No. BEC-OF-10).

\subsection{Selection of teeth}

41 single-rooted teeth were collected and placed in a $10 \%$ formalin solution until the experiment. Teeth were examined under a dental microscope (Carls Zeiss Meditec Inc., Göttingen, Germany) with 12.5x magnification to identify cracks, caries or resorptions. After examination, 28 teeth were selected for the experimental procedure. The surfaces of the roots were planed and washed with saline.

\subsection{Specimens preparation}

Teeth were decoronated at the CEJ level with a $0.2 \mathrm{~mm}$ disc (Yeti, Engen, Germany) with water cooling, horizontally sectioned in the apical third leaving a standard length of $10 \mathrm{~mm}$. The roots were cut along the axis with a $0.2 \mathrm{~mm}$ disc (Yeti, Engen, Germany) and divided into two parts. The 56 dentin specimens were examined under a microscope (Carls Zeiss Meditec Inc., Göttingen, Germany) with $12.5 x$ magnification to identify any cracks. No cracks were observed. 30 $\mathrm{mm}$ diameter oval, plastic molds were filled up with self-polymerizing resin (Interdent, Celje, Slovenia). Specimens were horizontally fixed on the resin surface (Fig. 1). As the Vickers hardness test requires a smooth and polished surface, the samples were polished with a carborundum disk and felt (Picodent, Wipperfürth, Germany) using $0.05 \mu \mathrm{m}$ aluminum oxide powder (Picodent, Wipperfürth, Germany) mixed with water.

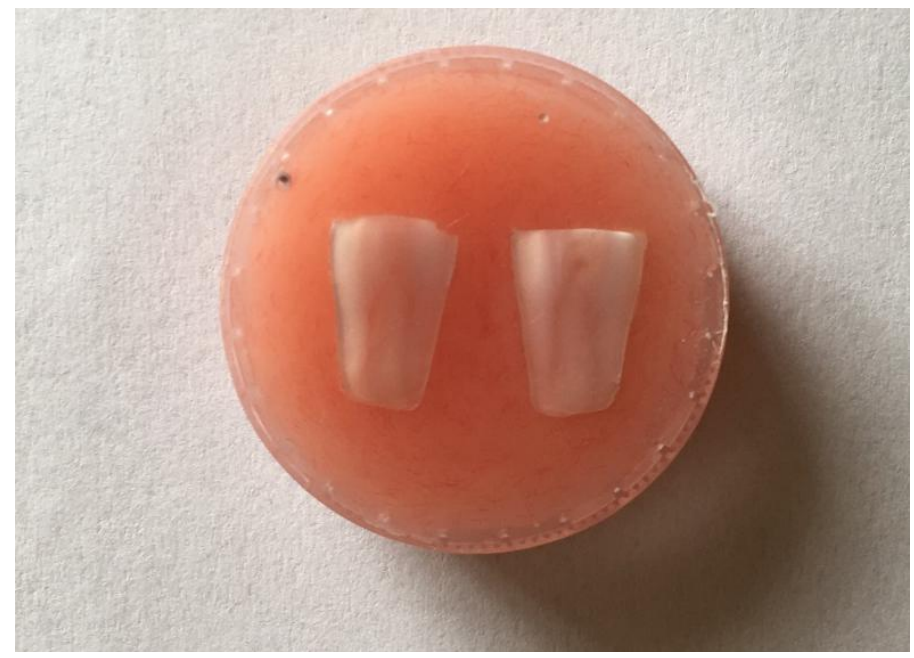

Figure 1.Prepared samples.

\subsection{Irrigation solutions usage}

For the testing in this study 17\% EDTA (i-dental, Vilnius, Lithuania), 2.5\% NaOCl (Cerkamed, StalowaWola, Poland), Dual Rinse HEDP (Medcem GmbH, Weinfelden, Switzerland) were chosen. Fresh Dual Rinse HEDP solution prepared in a sterile container according to the manufacturer's recommendations. HEDP powder of $0.9 \mathrm{~g}$ mixed with $10 \mathrm{ml} 2.5 \%$ $\mathrm{NaOCl}$ and stirred for 2 min. until dissolved.

Different final irrigation protocols for each group were provided as follows: $\mathrm{C}$ group $(\mathrm{n}=14)$ - control, dentin was exposed to saline for 1 min., E group ( $\mathrm{n}=14)$ - dentin was exposed to $17 \%$ EDTA for 1 min., ES group (n=14) - dentin was exposed to $17 \%$ EDTA for $1 \mathrm{~min}$. $+2.5 \% \mathrm{NaOCl}$ for $1 \mathrm{~min}$. ( $1 \mathrm{ml}$ distilled water was used between the solutions) 
and H group ( $\mathrm{n}=14)$ - dentin was exposed to Dual Rinse HEDP solution for 3 min. After the experimental procedure all specimens were rinsed with $2 \mathrm{ml}$ of distilled water.

\subsection{Vickers hardness test}

Dentin micro-hardness was determined by the Vickers hardness test. The specimens were mounted with a Vickers diamond indenter at $300 \mathrm{~g}$ load and a dwell time of $20 \mathrm{sec}$. The indentation was measured by a computer program using a 10x and 50x magnification optical microscope installed in the universal hardness measurement system (UH 250, Tukon, Germany). Three measurements (Fig. 2) were performed of each sample before and after the irrigation solution use and mean values were calculated (Fig. 3).

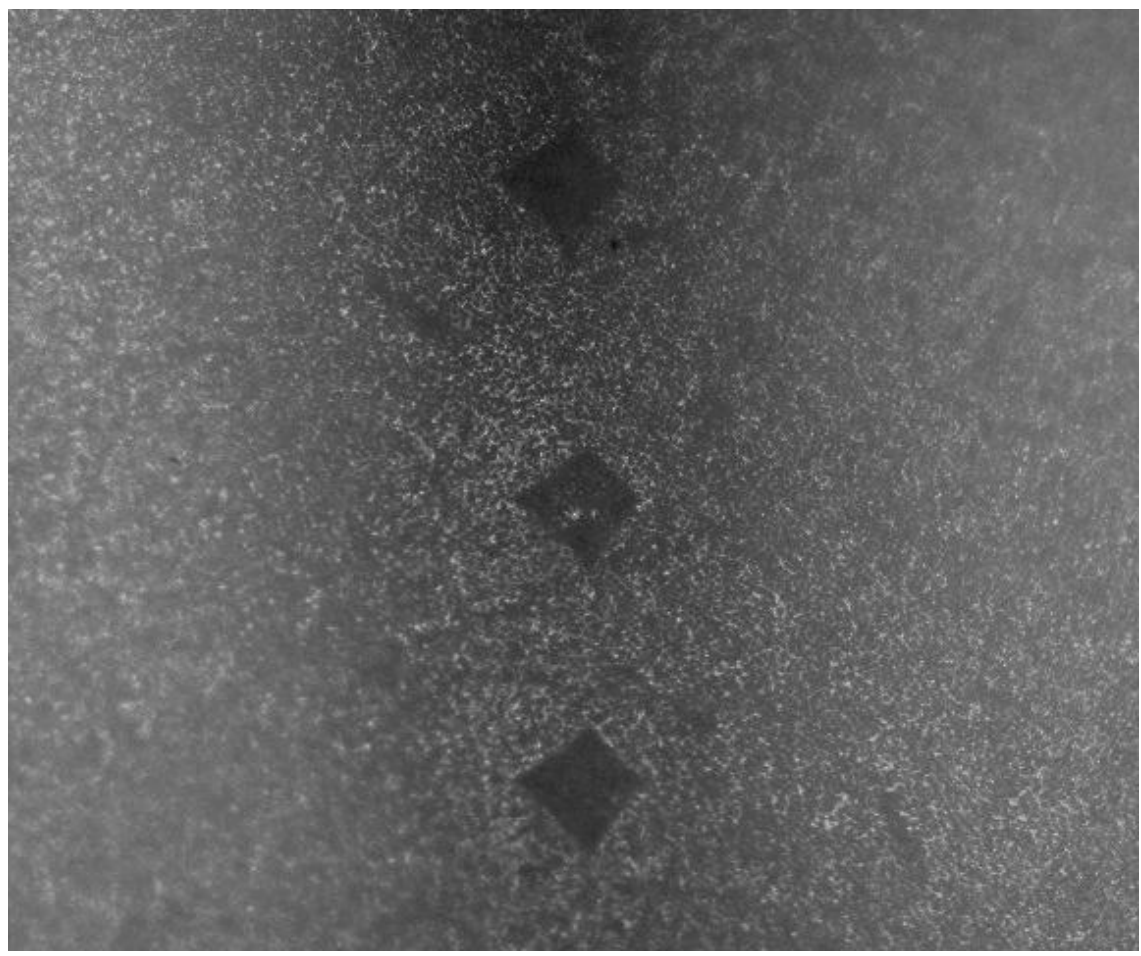

Figure 2. Indentations marked in the mid-root region.

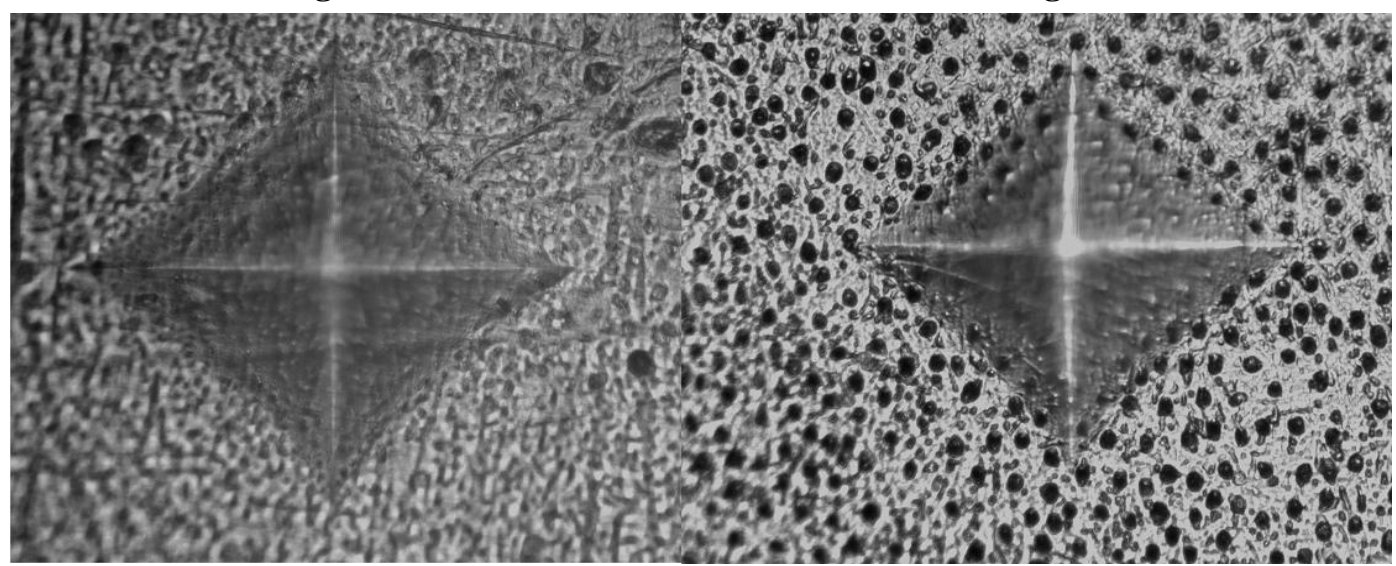

Figure 3.Indentation before and after Dual Rinse HEDP irrigation.

\subsection{Scanning electron microscopy}

Photographs were taken of randomly selected specimens from each group by scanning electron microscope (SEM) (Carl Zeiss EVO MA10, Göttingen, Germany) using 2000x magnification, EHT=10-20x.

\subsection{Statistical analysis}

Statistical analysis of the data was conducted using the SPSS 17.0 program. The Kolmogorov-Smirnov test was performed to verify the normality of the data. 
Inferential statistical analysis was performed using a Kruskal-Wallis and Mann-Whitney test to detect a significant difference between the groups. The Wilcoxon test was designed to examine the dependent groups. The level of significance was set at $\mathrm{P}<0.05$.

\section{Results}

Root canal dentin microhardness alteration before and after use of the irrigation solutions is shown in Table 1. All irrigation solutions significantly decreased root canal dentin micro-hardness compared to saline (control group) (P < 0.05). The greatest reduction was induced by Dual Rinse HEDP $(\mathrm{P}<0.05)$ while $17 \%$ EDTA and $17 \%$ EDTA $+2.5 \%$ $\mathrm{NaOCl}$ showed a similar reduction with no significant difference $(\mathrm{P}>0.05)$ (Fig. 4).

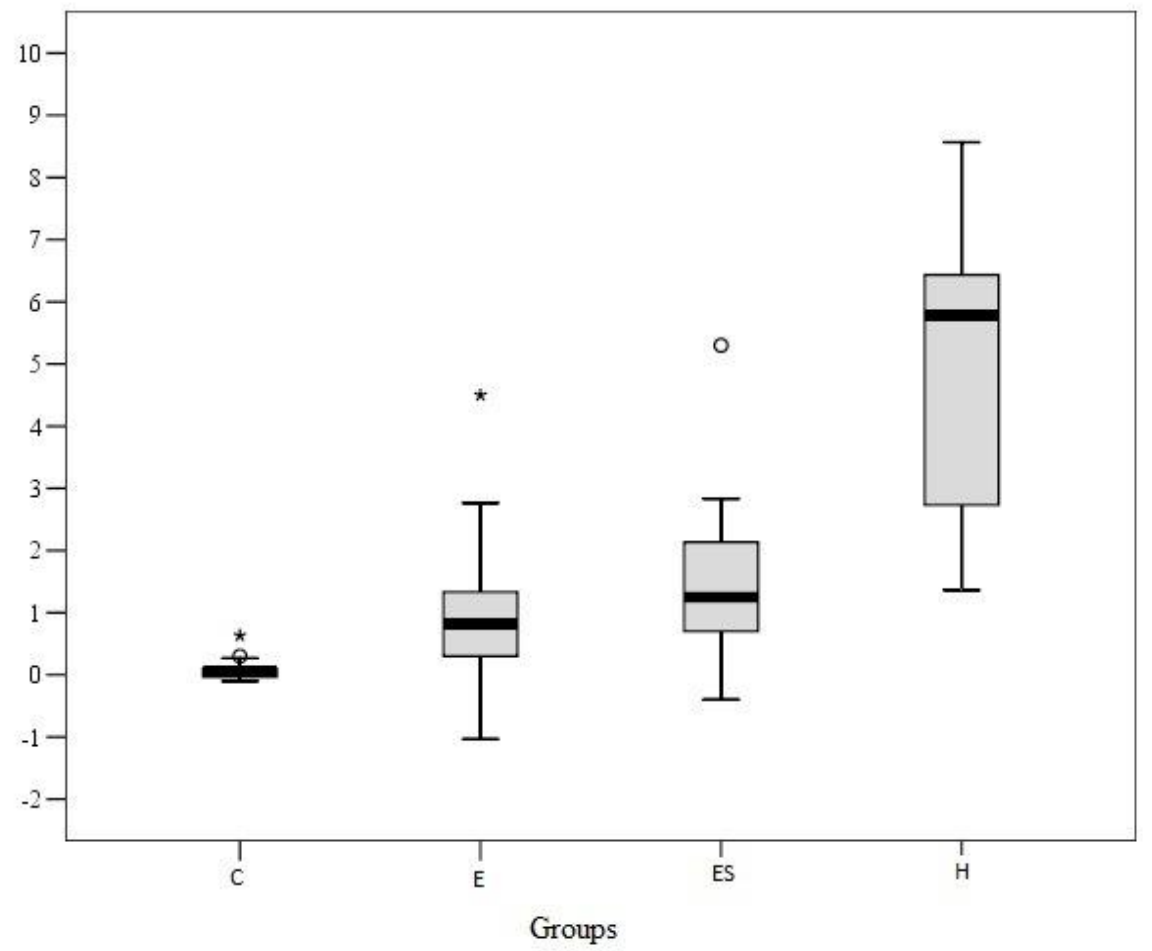

Figure 4. The mean of micro-hardness change observed among experimental groups.

\begin{tabular}{|l|l|l|}
\hline Group & Mean (SD) \\
\hline & Before & After \\
\hline C(Saline) & $52,89(2,93)^{\mathrm{a}}$ & $52,80(2,91)^{\mathrm{a}}$ \\
\hline E(17\% EDTA) & $52,55(5,40)^{\mathrm{a}}$ & $51,55(5,66)^{\mathrm{b}}$ \\
\hline $\begin{array}{l}\text { ES(17\% EDTA + } \\
2,5 \% \text { NaOCl) }\end{array}$ & $52,99(2,73)^{\mathrm{a}}$ & $51,42(2,48)^{\mathrm{b}}$ \\
\hline H(Dual Rinse HEDP) & $54,79(4,38)^{\mathrm{a}}$ & $49,74(3,61)^{\mathrm{c}}$ \\
\hline
\end{tabular}

Table 1.Values of root canal dentin micro-hardness before and after irrigation.SD, standard deviation; Different superscript letters indicate significant differences (analysis of variance, $P<0.05$ ). No pathological changes in the dentin surface were observed in SEM images. Erosion of the peritubular and intertubular dentin was not observed in either group (Fig. 5). 

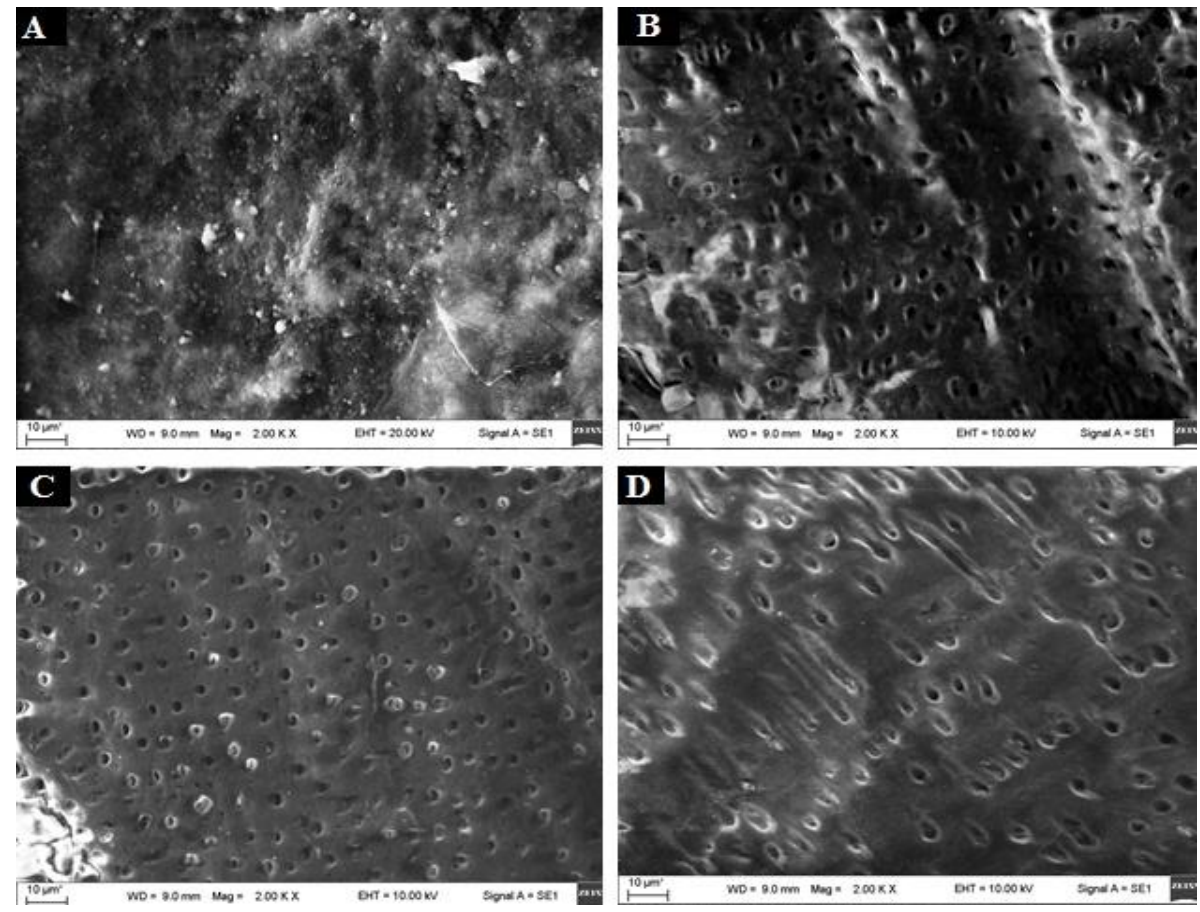

Figure 5.Scanning electron microscopy images of samples (2000 x). A (C group) - smear layer of the dentine. Uncovered dentin tubules, no visible erosion in all groups: B (E group), C (ES group), D (H group).

\section{Discussion}

The long-term prognosis of endodontic treatment depends on the quality of the instrumentation, disinfection and obturation of the root canal system. During irrigation, both coronal and root dentin are affected by irrigation solutions, what may have an impact on the physical and chemical properties including the dentin microstructure. Ideal irrigation solution should remove both the organic and inorganic parts in all thirds of the canal without damaging the dentine (Lofti et al. 2012). In this study, root canal dentin was not pretreated with instruments and $\mathrm{NaOCl}$ trying to avoid decrease in micro-hardness or causing the erosion because the purpose of research was to evaluate the effect on dentin of final irrigation solutions.

Widely used Vickers hardness test was chosen in this study because of its ability to assess the changes in human hard tissue due to chemical exposure (Kara et al. 2015, Ballal et al. 2010, Baldasso et al. 2017). This test could be used with all materials and test specimens as the procedure covers the entire hardness range and ensures indentation very clear and easy measure.

Micro-hardness of the dentin differs depending on the tooth area and number of tubules (Pashley et al. 1985). In order to obtain the most accurate results, in previous studies, dentin micro-hardness was measured before and after the use of irrigation solutions (Kara et al. 2015, Ballal et al. 2010, Aranda-Garcia et al. 2012, Dineshkumar et al. 2013). However, there are similar studies comparing micro-data only with the control group and not with pre-study data (Baldasso et al. 2017, Saghiri et al. 2012). In this study, dentin micro-hardness was measured before and after the use of irrigation solutions and compared to the control group with no effect.

When using EDTA, the recommended time for removing the smear layer is $1 \mathrm{~min}$. (Gautschi et al. 2009). In this study, the dentin surface had been irrigated by 17\% EDTA for $1 \mathrm{~min}$. what significantly reduced the dentin micro-hardness. This result is in agreement with other studies (Baldasso et al. 2017, Patil et al. 2011, Dineshkumar et al. 2012). Calt et al. 2002 concluded, that EDTA solution should be applied for a maximum of $1 \mathrm{~min}$. to avoid dentin erosion and found out that EDTA produces erosive effect in both peritubular and intertubular dentine, if exposition time is longer than 10 min. However, in most of the previous studies, EDTA was used longer than one minute, usually 3-5 min. or even 15 min., making the changes of dentin hardness more obvious (Patilet al. 2011, Lofti et al. 2012, Kara et al. 2015, Baldasso et al. 2017). Saha et al. (2017) used EDTA 17\% for 15 min., resulting in very significant micro-hardness change ranging from $56.88 \pm 1.48 \mathrm{VHN}$ to $43.12 \pm 2.51 \mathrm{VHN}$.

Sodium hypochlorite is associated with a significant decrease in micro-hardness in in vitro studies (Kara et al. 2015, Baldasso et al. 2017, Dineshkumar et al. 2012). In other study was found that EDTA significantly reduced dentin micro-hardness and caused erosion when the final irrigation with $2.5 \% \mathrm{NaOCl}$ was performed (Garcia et al. 2013). 
Greater dentin microhardness decrease after EDTA irrigation following $\mathrm{NaOCl}$ compare to EDTA use alone was obtained in this study but the difference was not significant. These results could be due to time the irrigation solutions affected the dentin - no longer than 1 min.

The effect of Dual Rinse HEDP on the dentin micro-hardness and dentin surface has not been studied before. In this study, the Vickers hardness test showed the greatest effect of this solution on dentin micro-hardness reduce compared to other irrigators. These results could be due to the long working time of the solution - $3 \mathrm{~min}$., which is recommended by the manufacturers. These results are in agreement with Tartari et al. (2015) study, where HEBP (editronic acid) significantly reduced dentin micro-hardness, although irrigation solutions interacted longer, HEBP did not interact with $\mathrm{NaOCl}$ at the same time and Knoop micro-hardness test was used instead of Vickers.

In this study, after evaluation the surfaces by SEM no dentin erosion was observed in the tested samples. However, there are contradictory results in the literature. $\mathrm{NaOCl}$ causes erosion of the dentin surface when used after the action of demineralizing solutions (Ballal et al. 2010). In Wang et al. (2016) SEM study was found that sodium hypochlorite $(3 \%, 5 \%)$ use after EDTA for 1 or $5 \mathrm{~min}$. induced dentin erosion. After removing the hydroxyapatite layer, the collagen collapsed immediately after sodium hypochlorite use (Baldasso et al. 2017). Saghiri et al. (2009) found that after 5 minutes of using EDTA and $\mathrm{NaOCl}$ for $5 \mathrm{~min}$. or $1 \mathrm{~min}$, erosion could be observed inside and around the dentin tubules but after $5 \mathrm{~min}$. erosion was more prevailing and this difference between groups was statistically significant. In other study, dentinal tubules erosion was promoted by using 17\% EDTA and 2.5\% NaOCl for 3 min. (Aranda-Garcia et al. 2013) but in this study, erosion of the dentin was not observed in either group. The contradictory results could be due to the time irrigation solutions affected the dentin. The time when irrigation solutions affect the dentin surface may be a crucial factor in the development of dentin erosion.

\section{Conclusions}

Irrigation solutions have not induced root canal dentin erosion, but significantly reduced the dentin micro-hardness. The greatest reduction was induced by Dual Rinse HEDP.

\section{Conflict of interest}

The authors have stated explicitly that there is no conflict of interests in connection with this article.

\section{References}

Aranda-Garcia AJ, Kuga MC, Chavéz-Andrade GM, Kalatzis-Sousa NG, Hungaro Duarte MA, Faria G, Reis Só MV, Faria NB (2013) Effect of final irrigation protocols on microhardness and erosion of root canal dentin. Microscopy Research and Technique76, 1079-1083.

Arslan H, Yeter KY, Karatas E, Yilmaz CB, Ayranci LB, Ozsu D (2015) Effect of agitation of EDTA with 808-nm diode laser on dentin microhardness. Lasers in Medical Science30, 599-604.

Baldasso FER, Cardoso LR, Silva VDD, Morgental RD, Kopper PMP (2017) Evaluation of the effect of four final irrigation protocols on root canal dentin components by polarized light microscopy and scanning electron microscopy. Microscopy Research and Technique80, 1337-1343.

Baldasso FER, Roleto L, Silva VDD, Morgental RD, Kopper PMP (2017) Effect of final irrigation protocols on microhardness reduction and erosion of root canal dentin. Brazilian Oral Research31, 40.

Ballal NV, Mala K, Bhat KS (2010) Evaluation of the effect of maleic acid and ethylenediaminetetraacetic acid on the microhardness and surface roughness of human root canal dentin. Journal of Endodontics36, 1385-1388.

Çalt S, Serper A (2002) Time-dependent effects of EDTA on dentin structures. Journal of Endodontics28, 17-9.

De-Deus G, Zehnder M, Reis C, Fidel S, Fidel RA, Galan J Jr, Paciornik S (2008) Longitudinal cosite optical microscopy study on the chelating ability of etidronate and EDTA using a comparative single-tooth model. Journal of Endodontics34, 71-5.

Dineshkumar MK, Vinothkumar TS, Arathi G, Shanthisree P, Kandaswamy D (2012) Effect of ethylene diamine tetraacetic acid, MTAD ${ }^{\mathrm{TM}}$, and HEBP as a final rinse on the microhardness of root dentin. Journal of Conservative Dentistry15, 170-173.

Gautschi SH, Sener B, Zehnder M (2009) Effects of ethylenediaminetetraacetic, etidronic and peracetic acid irrigation on human root dentine and the smear layer. International Endodontic Journal42, 335-343.

Grigoratos D, Knowles J, Ng YL, Gulabivala K (2001) Effect of exposing dentine to sodium hypochlorite and calcium hydroxide on its flexural strength and elastic modulus. International Endodontic Journal34, 113-119.

Kara Tuncer A, Tuncer S, Siso SH (2015) Effect of QMixirrigant on the microhardness of root canal dentine. Australian Dental Journal60, 163-168.

Lotfi M, Vosoughhosseini S, Saghiri MA, Zand V, Ranjkesh B, Ghasemi N (2012) Effect of MTAD as a final rinse on removal of smear layer in ten-minute preparation time. Journal of Endodontics38, 1391-1394. 
Pashley D, Okabe A, Parham P (1985) The relationship between dentin microhardness and tubule density. Endodontics and Dental Traumatology1, 176-179.

Patil CR, Uppin V (2011) Effect of endodontic irrigating solutions on the microhardness and roughness of root canal dentin: An in vitro study. Indian Journal of Dental Research22, 22-27.

Paulson L, Ballal VN, Bhagat A (2018) Effect of root dentin conditioning on the pushout bond strength of Biodentine. Journal of Endodontics44, 1186-1190.

Plotino G, Cortese T, Grande NM, Leonardi PD, Giorgio DG, Testarelli L, Gambarin G (2016) New technologies to improve root canal disinfection. Brazilian Dental Journal27, 3-8.

Saghiri MA, Delvarani A, Mehrvarzfar P, Malganji G, Lotfi M, Dadresanfar B, Saghiri AM, Dadvand S (2009) A study of the relation between erosion and microhardness of root canal dentin.Oral Surgery, Oral Medicine, Oral Pathology, Oral Radiology, andEndodontics108, 29-34.

Sayin TC, Serper A, Cehreli ZC, Kalayci S (2007) Calcium loss from root canal dentin following EDTA, EGTA, EDTAC, and tetracycline- $\mathrm{HCl}$ treatment with or without subsequent $\mathrm{NaOCl}$ irrigation. Journal of Endodontics33, 581-584.

Tartari T, Bachmann L, Zancan RF, Vivan RR, Duarte MAH, Bramante CM (2018) Analysis of the effects of several decalcifying agents alone and in combination with sodium hypochlorite on the chemical composition of dentine. International Endodontic Journal 51, 42-54.

Tartari T, Guimarães BM, Amoras LS, Duarte MA, Silva e Souza PA, Bramante CM (2015) Etidronate causes minimal changes in the ability of sodium hypochlorite to dissolve organic matter. International Endodontic Journal48, 399-404.

Ulosoy ÖI, Zeyrek S, Celik B (2017) Evaluation of smear layer removal and marginal adaptation of root canal sealer after final irrigation using ethylenediaminetetraacetic, peracetic, and etidronic acids with different concentrations. Microscopy Research and Technique80, 687-692.

Uzunoglu E, Aktemur S, Uyanik MO, Durmaz V, Nagas E. (2012) Effect of ethylenediaminetetraacetic acid on root fracture with respect to concentration at different time exposures. Journal of Endodontics38, 1110-1113.

Wagner MH, Rosa RA, Figueiredo JAP, Duarte MAH, Pereira RJ, Só MVR (2017) Final irrigation protocols may affect intraradicular dentin ultrastructure. Clinical Oral Investigations21, 2173-2182.

Wang Z, Maezono H, Shen Y, Haapasalo M (2016) Evaluation of root canal dentin erosion after different irrigation methods using energy-dispersive X-ray spectroscopy. Journal of Endodontics42, 1834-1839. 